\title{
El GÉNERO NARRATIVO DE TESTO YONQUI APROXIMACIÓN A LA DERIVA ENSAYÍSTICA de Paul B. Preciado
}

\author{
Pau Conde Arroyo \\ (Universitat de Barcelona)
}

\section{INTRODUCCIÓN}

Si con la postmodernidad llegan sucesivamente la muerte del autor, la crisis del sujeto y la extinción de los grandes relatos (por ende, también los que apuntalaban al sujeto y su subjetividad), ¿cómo y desde dónde se fragua la autobiografía en la postmodernidad, sin garantías de verdad y con todo el escepticismo postmoderno enfocado sobre su veracidad? En particular, después de la teoría queer y la consiguiente extinción de la legitimidad del gran relato [Lyotard 2016:73] sobre la presunta naturalidad de la coherencia entre sexo, género y deseo [Butler 2014:71-73], así como la declaración foucaultiana de la subjetividad como artefacto regulado biopolíticamente [Foucault 2016], ¿Cómo se compatibilizan la escritura del sujeto sobre sí mismo que pone en marcha la escritura autobiográfica con dicha regulación biopolítica, con la muerte súbita de la proclama de autenticidad de su subjetividad mediada por el género? ¿Es posible una escritura de corte empirista y subjetivista, como demanda la autobiografía como género literario, con la adscripción a los postulados queer? Y, más ampliamente, si la postmodernidad pone en jaque la solvencia del sujeto, ¿por qué en la producción literaria de las últimas décadas han proliferado las escrituras del yo, tales como la autoficción o el ensayo autobiográfico?

La emergencia de la subjetividad en el discurso como forma legítima del pensamiento podría indicar una mutación en la concepción retórica de la teoría queer. La presencia común de reflexión teórica y de narración autobiográfica en el ensayo queer de nuevo cuño invita a pensar desde otro lugar la definición taxonómica de los textos, así como las implicaciones teóricas de 
su hibridez discursiva. Sin presuponer una generalidad absoluta ni obviar que tanto la escritura académica dedicada a estos menesteres como la novela o el relato siguen, respectivamente, sus cauces habituales de teoría y de narración, es notable, al margen de estas, un incremento de la tendencia retórica heterogénea en lo que atañe a la producción ensayística que aborda asuntos relativos a la identidad, al feminismo y a la teoría queer. Testo yonqui (2015) de Paul B. Preciado es una obra paradigmática del viraje epistemológico producido por la teoría queer, pero, más allá del acatamiento a la consigna de lo personal es político y del saber situado que propugna el feminismo más reciente, lo que de narrativa autobiográfica hay en esta obra apunta también a otras cuestiones no menos importantes. La propuesta interpretativa de este artículo consiste, pues, en atender a la poética narrativa de Testo yonqui de Paul B. Preciado, como obra significativa de esta corriente híbrida, para, inductivamente, tratar de desgranar el valor de la autobiografía como artefacto literario en los nuevos cauces retóricos del ensayo queer, y enfocar así una posible respuesta al por qué de la mezcla discursiva y del consecuente sabotaje de las taxonomías literarias.

Testo yonqui se podría definir provisionalmente como un proyecto literario de autobiografía trans* que problematiza tanto al sujeto como al género literario en el que el sujeto se constituye como tal; aunque si bien no se puede definir la obra rotundamente como autobiografía stricto sensu, sí responde a una voluntad narrativa autobiográfica e indagatoria relativa al sujeto trans*. Se puede decir que es una autobiografía bastarda en dos sentidos distintos que operan simultáneamente: por una parte, en el sentido de genre, es un texto que transita por distintos formatos narrativos (como es sabido, en Testo yonqui se alternan capítulos narrativos, los impares, con capítulos dedicados a la reflexión teórica, los pares); y, por otra parte, en el sentido de gender [Mérida Jiménez 2010:1], como exploración identitaria que narra el tránsito de género de B. P., a nivel bioquímico y corporal y a nivel afectivo.

En Testo yonqui se tematizan simultáneamente el género de la autobiografía y la autobiografía del género, $y$, dada la insistente priorización de la segunda respecto a la primera en la bibliografía especializada, aquí se tratará de abordar la primera aun a riesgo de un enfoque

1 Las referencias a los nombres de los personajes se realizarán en función de las denominaciones presentes en el propio texto, por lo que el personaje-narrador de Testo yonqui será nombrado B. P. para distinguirlo del autor, Paul B. Preciado. Asimismo, se respetarán los géneros pronominales que aparecen en el texto para referir a cada uno de los personajes. 
sesgado. El planteamiento de este estudio es, por tanto, literario, aunque no se pueda adscribir plenamente Testo yonqui a dicha modalidad discursiva. La estructura de este artículo consta de tres apartados: el primero trata de atender a la autodefinición genérica del propio texto para tratar de dilucidar su poética narrativa desde Judith Butler, Paul de Man, Philippe Lejeune y Ángel Loureiro; el segundo recoge algunas críticas a la obra de Preciado a propósito del componente autobiográfico de Testo yonqui para observar cómo incide el marco teórico de la autobiografía en la recepción de su ensayo; por último, se problematiza la propuesta experimental de Preciado poniendo de relieve las tensiones relativas a su tratamiento de la (auto)representación estética y ético-política.

\section{LA HIBRIDEZ DISCURSIVA DE TESTO YONQUI Y \\ EL VALOR DE LA NARRACIÓN AUTOBIOGRÁFICA}

El género literario de Testo yonqui es planteado desde el inicio de la obra como problema, pues ya en el preámbulo hay un despliegue equívoco de autodefiniciones del texto que complican la primera definición proporcionada, aparentemente clara y sencilla:

\footnotetext{
Este libro no es una autoficción. Se trata de un protocolo de intoxicación voluntaria a base de testosterona sintética que concierne al cuerpo y a los afectos de B. P. Es un ensayo corporal. Una ficción, es cierto. En todo caso y si fuera necesario llevar las cosas al extremo, una ficción autopolítica o una autoteoría. [2015:17].
}

Planteo la necesidad de desconfiar, por lo menos en un primer momento, de la autodefinición inicial del texto, a fin de examinarla críticamente. Si, como se ha apuntado, es relevante tener presentes las dos acepciones de la palabra género (el literario y el sexual), el fragmento citado juega con los dos sentidos de la palabra ensayo: como género del discurso y como probatura experimental, como señala Mérida Jiménez [2010:8; 2016:100]. Los géneros apuntados en él son autoficción, protocolo, ensayo corporal, ficción, ficción autopolítica y autoteoría. Salvo el primer término, que aparece (sospechosamente) negado, los demás se presentan como sinónimos. Pero cabría preguntarse si un ensayo es acaso ficción; a lo que a priori se podría responder que no, o, al menos, la segregación de ficción literaria y de ensayo en las secciones de las librerías corrobora su (apriorística) desidentificación: mientras que la ficción propiamente dicha es asociada a la literatura (especialmente a la narrativa), el ensayo pertenece al ámbito comercial 
de la no-ficción.

Sin embargo, según su otra acepción (insinuada en el texto), si se define el ensayo como un experimento cuyo fin es verificar una determinada hipótesis (en tanto que «experimentación material» [Mérida Jiménez 2010:8]), el ensayo sería más bien, lejos de poder ser descrito como verdadero o falso, como verídico o ficcional, una prueba indagatoria que busca determinar los límites de lo real. Si se acepta la condición intrínsecamente tentativa del ensayo, entonces su semántica es doble, pues es tanto verdadera como falsa a la vez: es verdadera en tanto que parte de lo real para aprehenderlo más plenamente, y falsa en la medida en que desconoce la condición de verdad de las hipótesis que pretende demostrar. $\mathrm{O}$, dicho de otro modo, se podría plantear el género ensayístico (en cierto modo, literario y experimental a un tiempo) como la asignación conjetural tanto de verdad como de falsedad de un texto en relación consigo mismo. Según este planteamiento, el ensayo es un género limítrofe entre la ficción y la no-ficción, en consonancia con el carácter fronterizo de la autobiografía [Pozuelo Yvancos 2006:17-8], que juega «con el límite de la ficción/verdad» [2006: 18].

Por otra parte, podría considerarse que los términos ensayo, política y teoría devienen géneros ficcionales en Testo yonqui sólo en la medida en que se aplican al propio sujeto que los enuncia, es decir, cuando el sujeto de la enunciación coincide con el objeto del enunciado y, por tanto, «el sujeto [es] objeto de sí mismo» [Mauro Rucovsky 2011:169]. Serían entonces el ensayo, la política y la teoría géneros de no-ficción mientras que el ensayo corporal, la autopolítica y la autoteoría sí serían géneros de ficción. Pero esta hipótesis desemboca en una aporía, porque, si bien estos tres últimos géneros narrativos son ficciones relativas al sujeto, no son análogamente autoficciones, según se apresura a negar la primera aserción del libro: «No me interesan aquí mis sentimientos, en tanto que míos, perteneciéndome a mí y a nadie más que a mí. No me interesa lo que de individual hay en ellos. Sino cómo son atravesados por lo que no es mío» [Preciado 2015:17]. La relación entre el yo y lo pensado/teorizado, es decir, entre las dos modalidades discursivas que se alternan en Testo yonqui, escenifica un tránsito problemático entre particular y universal, como señala Tiberi a propósito del valor de la auto-hetero-biografía en el pensamiento de Derrida [2009:7-8]. Pues en Preciado no se trata simplemente de que la narración ilustre la teoría subordinándose así a ella (si lo hiciera claudicaría en su afán por desterrar la metafísica, cuyo gesto universalizador reduce la diferencia [Preciado 2005:162]), o, por 
el contrario, tampoco se trata de que la reflexión teórica acompañe instrumentalmente al relato del yo como la explicitación de sus razones o su mera justificación ideológica, sino que ambos discursos mantienen una tensión compleja y quizás irreductible.

Por otra parte, la exigencia de heterogeneidad en Preciado no se limita a dicha manifestación formal, sino que también impregna su concepción de la política queer, que debe aunar «estrategias a la vez hiper-identitarias y post-identitarias» [Preciado, 2005:162], así como aglutinar pensamiento teórico y activismo. Esta idea es afín a la idea adorniana de que teoría y praxis ni son lo mismo ni deben complementarse adjetivamente, sino que cada una conserva su entidad sustantiva suspendida en una tensión polarizada con la otra: «el dogma de la unidad de teoría y praxis, en contraste con la doctrina que invoca, es adialéctico: aprehende simple identidad allí donde únicamente la contradicción puede ser fructífera» [Adorno 2003:179].

Asimismo, cabría preguntarse por el grado de ironía² [Campagnoli 2018:401] que pudiera o no contener el citado enunciado inicial («Este libro no es una autoficción.» [Preciado 2015:17]), en vista de la urgencia por rechazar la autoficción como definición posible del propio texto para, no obstante, afirmar por separado el auto (autoteoría, autopolítica) y la ficción, así como ratificar en las páginas introductorias la vinculación entre escritura y vida (ensayo corporal, ficción, cuerpo experimental, sentimientos, subjetividad), pero sin mencionar en ningún caso el término autobiografía. «La insistencia en el carácter ficticio de su relato redobla la desmentida de la negación "no es una autoficción"» [Campagnoli 2018:401]. Es decir, explícitamente se niega la autoficción e implícitamente se apunta hacia alguna suerte de autobiografía anómala que necesita de otros géneros (ensayo corporal, teoría, política) para constituirse como tal, aun sin exceder su parcialidad. La reflexividad y la ficcionalidad del texto, pues, son definidas negativamente mediante una exclusión mutua que impide vincularlas en los marbetes de novela autoficcional, de novela sin ficción o de autobiografía novelada; esto en caso, claro está, de que el primer enunciado sea leído literalmente y no desde la desconfianza a la que podría conducir una lectura en clave irónica, en cuyo caso podría entenderse Testo yonqui como un ensayo-no-

\footnotetext{
2 Aunque aquí no se puede profundizar en este concepto por cuestiones de espacio, quede apuntado que la ironía es un mecanismo semántico muy importante tanto para la interpretación constructivista de la autobiografía [Pozuelo Yvan$\cos 2006: 25,34]$, que será comentada en este epígrafe, así como para cierta lectura psicoanalítica de la teoría queer, que caracteriza lo queer como pulsión negativa [Edelman 2014]; ambos planteamientos reelaboran la noción de ironía teorizada por Paul de Man [1998], y puede que influyan en la concepción retórica de ironía queer que caracteriza la prosa de Preciado.
} 
vela autoficcional, por su escritura eminentemente performativa al margen de la atribución de verdad avalada por una lectura referencial. Mérida Jiménez, por el contrario, lleva a cabo una lectura literal y señala que Preciado se desmarca de la autoficción [2010:9]; al no problematizar esta negación, la asume para definir el texto con la ambigua etiqueta de «autobiografía híbrida» [2010:9-10]. Aunque si bien la hibridez ${ }^{3}$ discursiva caracteriza, efectivamente, la textualidad de Testo yonqui, ello no implica necesariamente la invalidez de la atribución de autoficcionalidad a la obra.

Dicho rechazo incuestionado a una posible categorización de Testo yonqui como obra autoficcional (como un rasgo más de su hibridez tentacular) apunta, tal vez, al descrédito de la autoficción en tanto que praxis literaria, como método no ya epistémico, sino performativo de un saber que no es ni puede ser previo a la escritura misma. Esta lectura ampliaría el alcance del carácter performativo del texto, añadiéndole un tercer vértice: además de la capacidad epistémica de la teoría y de la práctica/ético-política de la conjunción de narración y teoría, habría una dimensión poiética en la narración autobiográfica que colmaría el sentido del relato al dotarlo de un grado máximamente performativo, «virtualidad creativa más que referencial, de poiesis antes que de mimesis: no es ya un instrumento de reproducción sino de construcción de identidad del yo.» [Pozuelo Yvancos 2006:33]. No se trataría, entonces, de establecer el grado de verdad del discurso por una mera cuestión de referencialidad [Gusdorf 1991:16], sino que la verdad misma del discurso se constituiría en él. Por lo que, quizás, pierde su sentido perseverar en el uso de la distinción de verdad y ficción en el texto. La autobiografía crea, por su propia estructura, la ilusión de un referente que supuestamente le sirve de modelo en tanto que se organiza miméticamente, pero cabe preguntarse con Paul de Man:

\footnotetext{
Y, puesto que la mímesis que se asume como operante en la autobiografía es un modo de figuración entre otros, ¿es el referente quien determina la figura o al revés? ¿No será que la ilusión referencial proviene de la estructura de la figura, es decir, que no hay clara y simplemente un referente en absoluto, sino algo similar a una ficción, la cual, sin embargo, adquiere a su vez cierto grado de productividad referencial? [1991: 113].
}

\footnotetext{
3 Pozuelo Yvancos señala su preferencia por el término de fronterizo frente al de híbrido para designar al texto autobiográfico [2006:17] precisamente por su «estatuto dual», entre la construcción o la invención y la descripción fiel de unos hechos, factor que diluye en cierto modo el carácter autobiográfico de los textos que dicen serlo, aproximándolos a lo que se conoce en literatura como autoficción, ya que «[es] cada vez más difusa la frontera entre los dos dominios.» [2006:35].
} 
Se diluyen las distinciones, y las polaridades (verdad y ficción, referente y copia, realidad y discurso, vida y autobiografía) se desfiguran en la medida en que los términos de la oposición se constituyen mutuamente, de modo que el orden causal por el que circula la verdad no es unívoco ni unidireccional (de lo real al discurso, o del discurso a lo real), sino ambiguo y múltiple, o, como dice Paul de Man: indecidible [1991:114]. La identidad del sujeto B. P. se apuntala en este espacio indecidible (y por ello, en parte también indecible [Moreiras 1991:129]), ficcional y autobiográfico, que es Testo yonqui. Análoga a esta ininteligibilidad referencial del texto, la propia narradora-personaje B. P. se ve abocada a su propia ininteligibilidad de género (por la falta de concordancia natura/ ${ }^{4}$ entre sexo, género y deseo), factor que la convierte problemáticamente en un sujeto abyecto [Butler 2015:19-20]: «Decido conservar mi identidad jurídica de mujer y tomar testosterona sin entrar en un protocolo de cambio de sexo.» [Preciado 2015:53].

El gesto deconstructivo de De Man [1990:149-150] respecto a la autobiografía y el de Butler $^{5}$ respecto al género presentan cierta familiaridad en la medida en que ambos parten de Derrida (quien, a su vez, retoma a Nietzsche [Pozuelo Yvancos 2006:24, 36, 40]), y la operación que realizan es similar: identifican una falacia en la causalidad que conduce la verdad desde su origen hasta sus desplazamientos, y que así da lugar a una serie de copias miméticas, de repeticiones que la justifican como verdadera según esta lógica causal. Las autobiografías fundamentan su veracidad en un referente real al que la escritura reenvía, y las actuaciones de género remiten a la verdad inapelable del sexo biológico; pero tanto autobiografía como género carecen, en un sentido parecido, de referente, pues lo producen como fenómeno inteligible. Por ello, se podría decir que, por analogía, la autobiografía y el género son performativos o realizativos: son actuaciones que fundan cierta verdad del sujeto que, sin embargo, dicen tan solo imitar según una ley o verdad previa a la que obedecen; esconden su performatividad fundacional bajo el disfraz de la referencialidad. Puesto que, en el ámbito literario, «toda narración de un yo es una forma de ficcionalización, inherente al estatuto retórico de la identidad y en concomitancia con una interpretación del sujeto como esfera del discurso.» [Pozuelo Yvancos 2006:24].

4 Es decir, dado un determinado sexo biológico (hombre o mujer), se sigue un determinado género que le corresponde (masculino para el hombre y femenino para la mujer), del que se sigue, a su vez, un deseo heterosexual por el género opuesto [Butler, 2014:71-3].

5 La pirueta metaléptica que funda la teoría queer está cifrada en la siguiente aseveración butleriana: «el sexo, por definición, siempre ha sido género.» [Butler 2014:57]. 
En este sentido, el género ensayístico en Preciado es doblemente productivo: por un lado, el género de la escritura autobiográfica ${ }^{6}$ se realiza a medida que se escribe, así como al sujeto cuya identidad construye textualmente; y, por otro lado, la escritura del género se realiza a sí misma en tanto que traducción textual del cuerpo generizado, es decir, que hace culturalmente inteligible la transición de género en la que se constituye el individuo transgénero, por lo que la escritura del género habilita la inteligibilidad del sujeto trans*. Ambos géneros relativos a su escritura contribuyen a la inteligibilidad del sujeto-personaje mediante su «delimitación narrativa» [Mauro Rucovsky 2011:170].

Así pues, mientras la lectura deconstructiva (Paul de Man [1990:151-153] a partir de Nietzsche y de Derrida) postula una ficcionalización del yo que permite leer la autobiografía exclusivamente desde su literariedad (llevando al extremo -hasta negarla- la tesis de la función cognoscitiva de la autobiografía postulada por Gusdorf, De Man hace hincapié en el factor performativo del texto [Loureiro 2001:135, 148]), por el contrario, la lectura pragmática de la autobiografía

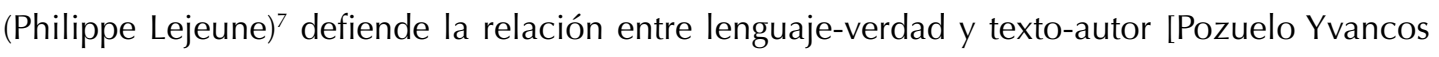
2006:24, 41, 53] sobre la base del contrato de lectura (Ilamado pacto autobiográfico) que establece la coincidencia entre la identidad de autor, narrador y protagonista [Lejeune 1991]. Como reacción a estas dos corrientes interpretativas, surge una tercera que, en lugar de atender al factor estético o bien al referencial/veritativo de la autobiografía, atiende a su compromiso ético (Ángel Loureiro a partir de Levinas) como función literaria que establece un pacto ético con el lector; por lo que, para Loureiro, lejos de una voluntad autorreferencial y solipsista (en los deconstruccionistas) y de su valor documental e histórico (en los pragmáticos), el motor de la escritura autobiográfica radica en dicha responsabilidad ética hacia el otro [Loureiro 2001; 2016].

De modo que, si, como se ha apuntado, Testo yonqui manifiesta su identidad discursiva en lo que viene a ser una suerte de poética en las páginas preliminares, no parece que haya, no obstante, una adscripción unívoca ${ }^{8}$ a un enfoque particular sobre el modo de entender el arte-

\footnotetext{
6 Por ahora, este artículo mantendrá el carácter indecidible entre autobiografía y autoficción del marco demaniano, pese a emplear el término autobiografía por motivos de economía lingüística; no por ello se implica que la discusión en torno a ambos se haya clausurado. Esta cuestión será retomada más adelante.

7 Se ha elegido este orden argumentativo por la secuencia expositiva que el presente artículo ha seguido hasta ahora, pero cabe señalar que el texto de Lejeune es previo al de De Man y que, de hecho, De Man escribe el suyo en oposición al de Lejeune.

8 Téngase en cuenta, además, que Preciado, como discípulo de Derrida, se situaría a priori en el paradigma deconstructivo de entender la autobiografía.
} 
facto literario de la autobiografía; y es en este sentido que resulta ambiguo el valor otorgado a la narración autobiográfica en Testo yonqui, en que el pacto de lectura propuesto por el texto es ambivalente. A fin de examinar esta cuestión, y teniendo presente que las distintas perspectivas constituyen «órdenes analíticos [distintos e] (...) irreductibles y que no se dan en el mismo lugar epistemológico» [Pozuelo Yvancos 2006:43], a continuación se presentan brevemente algunos indicios textuales ${ }^{9}$ de Testo yonqui que corroboran cada uno de los tres posibles sentidos de la narración autobiográfica:

a) la dimensión performativa: «aquí el nombre es otra fábula» [2015:15], «[Este libro] es un ensayo corporal. Una ficción, es cierto.» [2015:17], «(...) este es el modo en que construye y deconstruye la subjetividad.» [2015:18], «Este libro no tiene razón de ser fuera del margen de incertidumbre que existe entre yo y mis sexos, todos imaginarios» [2015:25], «queremos hacer [G. D. y B. P.] autoficción política sobre el proceso de recombinación genética de tu esperma sidoso y mis óvulos de bollera trans.» [2015:160], «[La filosofía es] un ejercicio de lenguaje que produce como residuo una ficción política (individual o colectiva) que no existía antes de comenzar ese discurso.» [2015:285].

b) la dimensión pragmática: «Este libro fue escrito antes de ese cambio [de nombre] y por ello todas las iniciales se han conservado. Sin embargo, la firma, al mismo tiempo rastro, tachadura y promesa, ha sido modificada. Entiéndase que Paul absorbe y asume todo lo que un día fue B. P.» [2015:15] ${ }^{10}$; «una experiencia (...) cuya duración exacta fue de doscientos treinta y seis días y noches y que continúa hoy bajo otras formas.» [2015:18].

c) la dimensión ética: «aquí el nombre es otra fábula: pero esta vez colectivamente compartida. Os toca ahora a vosotros otorgarme el derecho a llevar esta máscara.» [2015:15], «Para algunos, este texto podrá hacer oficio de un manual de bioterrorismo de género a escala molecular. (...) Expongo al lector estas páginas que relatan los cruces de teorías, moléculas y afectos para dejar una huella de una experiencia política» [2015:17-

9 Si bien es cierto que los órdenes analíticos propuestos se refieren no tanto a la producción autobiográfica como a su recepción, puede resultar esclarecedor atender en primer lugar al propio texto en la medida en que Testo yonqui es un ensayo altamente autorreflexivo (e, incluso, autorreferencial), pues su «Escritura da cuenta de sí misma» [Mauro Rucovsky 2011:171].

10 Esta aclaración no estaba en la primera edición de la obra, pues fue añadida a la edición de 2015. 
18], «La escritura es el lugar en el que habita mi adicción secreta y, al mismo tiempo, el escenario en el que mi adicción sella un pacto con la multitud.» [Preciado 2015:50], «Mi cuerpo: el cuerpo de la multitud.» [2015:164].

Las autodefiniciones de Testo yonqui en tanto que inscrito en múltiples géneros literarios y partícipe de distintas dimensiones del factor autobiográfico, además de tratar de sabotear la lógica taxonómica de los géneros (literarios y sexuales a un tiempo), son relevantes en la medida en que condicionan la recepción del texto: ponen en juego la condición de verdad de lo narrado; y es éste el motivo de que la mayoría de las citas procedan de las páginas preliminares, pues es en ellas donde se encuentra más explícita la poética de la obra ${ }^{11}$. «La presencia en toda autobiografía de discursos heterogéneos y en conflicto entre sí pone de relieve la inestabilidad intrínseca a la autobiografía como género, (...) que es abordada explícitamente por muchos autobiógrafos modernos en forma de reflexiones metaficcionales» [Loureiro 2001:148]. Así pues, según lo expuesto, parece pertinente en el caso de Testo yonqui conjugar tanto una lectura estético-performativa como ético-política de la autobiografía (pragmática en menor medida, pues, a pesar de que las citas de (b) podrían dar pie a dicha lectura, esta perspectiva colisiona con el sentido predominante del texto, como se advierte por (a) y por (c). Sin embargo, retomando la cita anterior de que el movimiento queer debe integrar «estrategias a la vez hiper-identitarias y post-identitarias» [Preciado, 2005:162], podría leerse esta consigna a la luz de las citas de (a) y (b) desde la perspectiva crítica de la autobiografía como una afirmación de la coexistencia tanto del apego a la identidad como de su rechazo (además Testo yonqui subraya la desidentificación como posición crítica [2015:254]), o, lo que podría ser su traducción a las perspectivas analíticas expuestas: las citas de (a) y (b) denotan una tensión irreductible entre la comprensión de lo autobiográfico en clave pragmático-referencial a la vez que en clave estético-performativa. En todo caso, al margen de esta hipótesis, Preciado sostiene en otro texto que:

\footnotetext{
Any editor of any magazine or academic journal would advise that I insert here a note saying that "I", the author of this text, am not the subject to which this narrative refers. In fact, I am not. The personal pronoun here doesn't refer to my own body or my sexuality (which on one hand, are not my property, and on the other hand, are nobody's business) but to your body and to your sexuality, as far as it is you who, reading this text, become the subject to whom I refer. [2017:134].
}

11 Además del capítulo dedicado al principio autocobaya, que será examinado en el último epígrafe de este artículo. 
Esta cita aglutina explícitamente tanto la dimensión performativa como la ética, y su sentido inhabilita la hipótesis de la lectura en clave referencial ${ }^{12}$. Respecto al salto de lo ético a lo político en la tercera dimensión mencionada, este desplazamiento no consiste meramente en la sustitución del pronombre tú por el vosotros en el apóstrofe, sino que, sobre todo, el peso político del apóstrofe viene dado por la mención de la multitud (presente inclusive en otros textos de Preciado [2005]), conformada por la unión del vosotros y el yo en un nosotros multitudinario [Campagnoli 2018:402,432]. Esta multitud queer, que remite a la matriz política de Hardt y Negri [Preciado 2005:158], además de a la matriz foucaultiana, ha sido descrita por Campagnoli como sujeto político y monstruo biopolítico [2018:151-162], pues para «colectivizar políticamente la infamia (...) enlaza la primera persona del plural» [Mauro Rucovsky 2015:15]. Por ello, pese a que la ética de la autobiografía que propone Loureiro es ajena a la política en la medida en que «El otro [ético] de Levinas es anterior a toda construcción política del sujeto» [2001:137], la escritura de Preciado, no obstante, permite reformular este planteamiento para hablar de una ética-política queer del ensayo autobiográfico cimentada simultáneamente en la forma vocativa de hablar al otro en la que se constituye el yo [Loureiro 2001:137], en la consecuente dimensión relacional del texto y en la articulación política de la diferencia en la multitud queer.

Asimismo, la responsabilidad ética con la alteridad no solo es patente en los apóstrofes citados de (c) sino también en las relaciones de la protagonista con los personajes de V. D. y G. D., quienes materializan en el seno de la narración las pulsiones de vida y muerte, respectivamente, a la vez ejes constitutivos de la protagonista (enamoramiento y duelo) y ejes narrativos del relato (que inicia y finaliza con la mención de la muerte de G. D., y los episodios intermedios tematizan ampliamente la relación entre B. P. y V. D. [Mirizio 2009:343; Campagnoli 2018:399, 403, 406]). La «fundamentación ética de la escritura como responsabilidad» [Loureiro 2001:145] se conjuga, pues, con una «ética de la narración abyecta y subalterna» [Mauro Rucovsky 2011:168] a la que conduce «El deslizamiento (...) de ciertas ficciones literarias al campo de las ficciones políticas (...), desliz de una dimensión estética (ficción literaria) a una política (ficción política)» [2011:167]. Por lo que la autodefinición del texto como autopolítica puede ser entendida, por un lado, como la colectivización del relato del yo, y, por otro lado, como un pacto ético-político

12 Apunta en esta misma dirección la cita de La niña del pelo raro de David Foster Wallace que encabeza el ensayo Pornotopía de Preciado. 
con la multitud (como denota el énfasis en lo colectivo en los ejemplos citados de (c)).

\section{LA RECEPCIÓN DE LA NARRACIÓN DE TESTO YONQUI}

\section{Y EL PROBLEMA DE LO REAL EN EL TEXTO}

Si bien las tres dimensiones mencionadas se superponen de modo complejo en Testo yonqui, en general su recepción por parte de la crítica, en cambio, resulta comparativamente uniforme: la lectura mayoritaria del texto se ha realizado en clave pragmático-referencial, factor determinante que ha propiciado múltiples críticas al valor de la narración autobiográfica en el ensayo de Preciado. Sin afán de exhaustividad, este epígrafe se propone examinar brevemente algunas de dichas críticas ${ }^{13}$ con el objetivo de contrastarlas con la exposición anterior sobre el valor otorgado por el propio ensayo a su componente autobiográfico.

En consonancia con las múltiples autodefiniciones categoriales de Testo yonqui examinadas en el epígrafe anterior, es significativa la definición de la obra que propone cada trabajo crítico: mientras Rafael Mérida Jiménez, ya citado, emplea los términos recuento personal, ensayo y autobiografía híbrida [2010:8-10], Annalisa Mirizio emplea el de testimonio [2012:175, 178], además de retomar los términos de ficción autopolítica y autoteoría [2012:173], ya presentes en la obra de Preciado. Gerard Coll-Planas, por el contrario, evita definir el texto con nociones unívocas, pero lo describe igualmente según los mismos parámetros referenciales, catalogándolo, así, dentro de la literatura testimonial: «alterna las reflexiones teóricas con textos en los que se nos presenta en su piso de París autohormonándose con testosterona» [2012:79]. Ana de Miguel, por su parte, describe el texto de un modo similar diciendo que «aúna discurso filosófico con relatos de su vida.» [2015:139]. Por otra parte, Mabel Alicia Campagnoli aporta una valoración más matizada, pero termina definiendo la faceta narrativa de la obra como diario íntimo: «[Testo yonqui] tiene un formato de diario íntimo e incluso la edición emula a un cuaderno para notas de campo, de los que usaran los antropólogos franceses en sus trabajos etnográficos. El libro tiene la peculiaridad de ser un ensayo con matices autobiográficos» [2018:72] y, en otro momento, reitera que la obra es un «híbrido entre ensayo, diario íntimo y cuaderno etnográfico de campo

13 Para la elaboración de este epígrafe ha sido de gran utilidad el capítulo que Mabel Alicia Campagnoli dedica a la recepción de Preciado [2018:79-117], especialmente aquel dedicado a las críticas relativas a la "Autoexperimentación textual-química-filosófica» [2018:103-109], así como las referencias citadas por Luisa Posada Kubissa en su capítulo sobre la filosofía de Preciado [2019: 223-253]. 
(...), [que] habilita una reflexión filosófica sobre experiencias personales intensas» [2018:399]. Por último, Luisa Posada Kubissa alude al texto mediante los términos auto-narración y ensayo-biográfico [2019:247], así como con el de texto-testo [2019:242] (en referencia a la paronomasia que produce la apócope de testosterona presente en el título), y añade que «[e]ste ensayo es una narración de las propias experiencias de Preciado» [2019:235]. Asimismo, cita múltiples trabajos dedicados a Preciado, de los que destacan tres por aventurarse a definir la obra: Aquiles Zambrano, quien define el texto como diario [2019:234], Juliana López Pascual, quien sostiene que «el involucramiento personal de la filósofa es innegable, lo que a lo largo de las páginas plantea sistemáticamente la duda ¿este es un libro sobre política y sexualidad? ¿O se trata de un libro sobre Beatriz Preciado?» [2019:248], y el estudio de Mérida Jiménez antes citado, del que Posada Kubissa cita, entre otras cosas, que «Beatriz baña su relato de autenticidad autobiográfica» [Posada Kubissa 2019:242; Mérida Jiménez 2010:7; 2016:9].

Se advierte que la mayoría de definiciones citadas inciden mucho más en el componente autobiográfico que en el propiamente narrativo e, incluso, en algunos casos, más que en el aspecto ensayístico o teorético (aunque algunos de los ejemplos equiparen la relevancia de lo ensayístico y lo autobiográfico, marginan, sin embargo, el factor literario de la narración). Esta priorización de lo autobiográfico implica un marco de lectura pragmático-referencial en sentido lejeuniano (no explicitado siquiera en la mayoría de los trabajos críticos) que corre el riesgo de despojar al texto de su valor estético y performativo. Es significativo, en este sentido, el empleo del vocablo autenticidad en la última cita como ratificación del carácter verdadero del texto, pues, en función de la supuesta correspondencia entre autor y narrador, «el lector se convierte en juez, en poder policial encargado de verificar la autenticidad de la firma y la consistencia del comportamiento del firmante, el punto hasta el que respeta o deja de respetar el acuerdo contractual que ha firmado» ${ }^{14}$ [De Man 1991:114]. Cuando «el yo emerge como sujeto de la propia narrativa (...) [aparece la] retórica de la franqueza donde habla de lo íntimo» [Mauro Rucovsky 2011:169], sin embargo, «[l]a pretensión de sinceridad narrativa se desenmascara como autoengaño epistémico.» [Mauro Rucovsky 2011:174].

Pero si, como sostiene De Man, el espacio entre ficción y realidad es indecidible en la

14 La cursiva es mía. 
retórica autobiográfica [1991:114], ¿Cómo distinguir el carácter verdadero del texto para inscribirlo dentro de los parámetros testimoniales que permitirían describirlo como, efectivamente, auténtico? Y, en consecuencia, si es también estrictamente indecidible la diferencia entre autobiografía y autoficción, ¿por qué no contemplar la autoficción como definición más que posible de un texto que no cesa de declarar su carácter performativo? Estos interrogantes nos conducen a inquirir, retomando las pesquisas del epígrafe anterior, si acaso tiene alguna cabida la autoficción (aunque sea una etiqueta parcial, sin duda) en Testo yonqui; no obstante, solo tres de los autores de la bibliografía consultada consideran la autoficción como posibilidad (aunque sea de forma fugaz para descartarla): Mérida Jiménez, Mauro Rucovsky y Campagnoli. Respecto al silencio de los demás, se podría intentar la siguiente hipótesis: ¿y si la asunción tácita e incuestionada de los parámetros referenciales de lectura fuera lo que les permite construir sus respectivas críticas a Testo yonqui, no desde el disenso argumentado de acuerdo con cuestiones formales o ideológicas, sino más bien desde descalificaciones que adoptan formas sospechosamente parecidas a las falacias ad hominem? Sería el caso de aquellas críticas que arremeten contra algún elemento narrativo del relato autobiográfico (tal como, por ejemplo, la polémica narración del despertar sexual de B. P. en la infancia [Preciado 2015:77-80]) para impugnar la validez de ciertos aspectos teóricos (siguiendo con el ejemplo anterior, interpretar lo narrado como misógino y, de ahí, inferir en el plano teórico que la reivindicación de identidades y prácticas disidentes encubre una suerte de neomachismo que opera como sustrato de la teoría queer, y cuyo objetivo principal es el borrado del significante "mujer" [Mirizio 2012: 175-178; Ana de Miguel 2015: 140141; Posada Kubissa 2019]). En sentido análogo, otras críticas fundamentan sus argumentaciones en una premisa no explícita (que incurriría en falacia ad hominem a la vez que en petición de principio) que distinguiría lo queer de lo trans* como ámbitos irreconciliables en una misma persona para así probar la falta de legitimidad del discurso teórico de Testo yonqui que impugna el discurso médico-jurídico sobre la transexualidad, en virtud de que la narradora-protagonista del relato no es del todo trans*15 [Coll-Planas 2012:79-84; Mauro Rucovsky 2015:104, 162-163].

15 Esta cuestión merecería un tratamiento más matizado que aquí no puedo desplegar por cuestiones de espacio. Cabe señalar, sin embargo, que hay una parte de la crítica de estos dos autores que me parece acertada, pero lo que aquí quería señalar, insisto, es algo de otro orden: no tanto los argumentos en sí, como la operación de impugnar a Preciado-autor por (supuestamente) carecer de legitimidad para sostener tal o cual idea porque, a juicio de los críticos, no demuestra ser lo suficientemente trans* en su relato autobiográfico; pasando por alto la confusión entre autor y narrador, entre vida y obra, se podría objetar que es arbitraria esa manera de establecer unos criterios a priori que definen la exterioridad de lo trans* o lo queer de un modo próximo al esencialismo. Aunque de distinto modo, ambos autores defienden que 
Por otra parte, la lectura referencial que opera en esas críticas podría estar clausurando el posible nivel irónico contenido en el tono provocativo del texto; es decir, la interpretación literal de lo narrado, derivada de una lectura estrictamente referencial, podría obturar un posible estrato irónico o paródico, tanto en la narración como en el discurso ensayístico (en este sentido, los ejercicios de política-ficción que pueblan la obra juegan a sabotear el sentido unívoco de su lectura). Se podría entender incluso la ambigüedad del texto respecto a su propia definición formal como resultado del hipotético juego irónico de la obra; en ese sentido, retomando el interrogante por la autoficción, Campagnoli se pregunta por la ironía latente en el primer enunciado para plantear el posible pacto de lectura que establece el texto en aras de una velada intencionalidad: «si se trata de una ironía para establecer el pacto autobiográfico con quien lea o más bien de un énfasis para que nos detengamos en la teorización antes que en las calientes descripciones sexuales.» [2018:401]. Campagnoli señala, además, la ambigüedad entre autobiografía y autoficción en Testo yonqui, pero su análisis se encauza en los parámetros lejeunianos que le permite la etiqueta del diario íntimo [2018:402-404].

\section{LA POÉTICA SNUFF DEL PRINCIPIO AUTOCOBAYA}

\section{Y EL PROBLEMA DE LA REPRESENTACIÓN}

Como ya se ha comentado, el problema de lo real y del referente en la autobiografía no radica propiamente en el texto, sino en su recepción. Ahora bien, los ejemplos glosados son reveladores en la medida en que no solo manifiestan ciertos marcos de lectura implícitos, sino también porque operan en función de la propia ambigüedad del texto, del que podría decirse que juega a establecer múltiples pactos de lectura, algunos de los cuales en tensión interna entre sí. Esta problemática se manifiesta con especial fuerza en el principio autocobaya, formulado en el doceavo capítulo de Testo yonqui (el último capítulo teórico). Este principio es una suerte de propuesta experimental presentada como un manifiesto que trata de vincular autoconocimiento y política en aras de la desactivación de la biopolítica operativa en la propia subjetividad [Preciado 2015:244-246]. Si bien esta cuestión excede los límites a los que se ciñe este artículo (en

Preciado instrumentaliza las vidas trans* para articular su propuesta política queer [Coll-Planas 2012:81-84; Mauro Rucovsky 2015:185], ¿pero, desde un marco de lectura lejeuniano, no sería acaso su propia vida la única que es puesta al servicio de la teoría queer? 
tanto que no forma parte del conjunto de capítulos narrativos de la obra), conviene tratar de desgranar sucintamente el sentido del principio autocobaya, en la medida en que contiene las claves de lectura para entender el artefacto narrativo de Testo yonqui y su articulación estética y ético-política.

Dicho principio constituye una clara apuesta por una filosofía de corte subjetivista y empirista (o, más bien, autoempirista) que se inscribe en una tradición de pensadores heterodoxos que experimentaron los efectos de determinadas sustancias en sus propios cuerpos [Preciado 2015:246-252]. Esta postulación es nuclear en el ensayo y parece que es la que dota de sentido al auto de la autoteoría y la autopolítica enunciadas en el preámbulo [2015:17], y, aparentemente, permite descartar la etiqueta de la autoficción. Debido a que la vertiente epistémica de la propuesta consiste en experimentar con las ficciones somáticas y los códigos semiótico-técnicos impresos sobre ellas [Preciado 2015:93-94, 245] para desnaturalizarlas (en ello consiste la vertiente ético-política), se niega, por consiguiente, la autoficción como definición del propio texto, y que luego es desgajada en el auto y la ficción. La propuesta autoexperimental, en principio, no consistiría en elaborar literariamente parte de lo real (tal como la figura autorial en la autoficción) para convertirlo en ficción o imprimirle su valor en tanto que producto literario, sino en desenmascarar las ficciones culturales impuestas sobre el sujeto. De modo que cabría entender el principio autocobaya como una consigna propositiva a la vez que como una declaración de intenciones retrospectiva que obligaría a reconfigurar la clave de lectura del relato auto-ficcional-biográfico.

Se trataría de ejercer una «resistencia a la normalización» [2015:244] biopolítica desde dentro, subvirtiendo el panóptico comestible [Preciado 2015:128-139], constituido, en el caso de B. P., por las hormonas sintéticas, para posibilitar un «agenciamiento crítico» [2015:244] respecto a las construcciones culturales que subjetivan y sujetan al sujeto, ya que, foucaultianamente, «cada instrumento de control es al mismo tiempo una potencialidad subversiva o de distorsión de los mecanismos del poder» [Smiraglia 2011:2]. De este modo, «más que de una nueva identidad de género, se trata de una forma de gestión de la propia identidad a través del des-reconocimiento, la des-identificación y la des-posesión, donde parece ubicarse su potencial político» [Campagnoli 2018:419-420].

En consecuencia, no solo se deniega, en sentido literal, la definición autoficcional del 
texto, sino también la estrictamente autobiográfica, porque el principio autocobaya no es ni pretende ser un ejercicio autobiográfico, pues, si bien se propone abordar el propio cuerpo y lo experiencial desde la comprensión de las operaciones semióticas y biotécnicas que inciden en la subjetividad, no consiste, no obstante, en hablar desde el yo para hilvanar un relato autobiográfico que dé cuenta de la irreductibilidad de lo individual, inaprensible por el pensamiento abstracto. Se trata, por el contrario, del sacrificio de lo individual: el yo y sus particularidades contingentes, según este principio, deben inmolarse en cierto modo en aras del potencial epistémico del experimento. El principio autocobaya dictamina que el sujeto y su cuerpo son la plataforma experimental que permite la vivisección [Preciado 2015:249, 302-303], pues lo que se disputa no es la singularidad de cada cual, sino la prefabricación compartida de las subjetividades irrepetibles.

Así pues, se podría decir que el principio autocobaya radica en una suerte de auto-experimento-ficcional-performativo a la vez que en una antiautobiografía. Lo que está en juego es la relación implícita entre universal y particular; y, fuera de establecer el valor epistémicamente preferente en la senda unidireccional del tránsito de uno de los dos términos hacia el otro, Preciado problematiza esas nociones en el principio autocobaya y propone una bidireccionalidad compleja y, en principio, no universalizable: su teoría no puede ser transferible a otros sujetos (pues sólo así preservaría su valor de autoteoría). Por otra parte, el sabotaje de los límites entre géneros requiere, para su coherencia, el consiguiente sabotaje de las taxonomías literarias; la antiautobiografía de la autocobaya posee, pues, idéntico carácter performativo que la autoficción literaria posmoderna, aunque su punto de partida sea distinto. A propósito del carácter performativo del experimento, Campagnoli identifica un giro hacia la narrativa en los estudios culturales: «si los estudios culturales cruzaron posestructuralismo con pragmatismo y produjeron el quiebre de la jerarquía entre saberes, todo relato es ficción (...) Así, la auto-biografía deviene auto-ficción» [2018:399-400], ya que «la auto-ficción ${ }^{16}$ (...) interpela la función performativa del lenguaje en su dimensión de programación de género» [2018:418].

Ahora bien, si aceptamos con Preciado el nulo valor de verdad de toda representación, aun cuando parta de lo real, si «la pornografía (...) revela que la sexualidad es siempre y en todo

16 El guion entre auto y ficción señala que la auto-ficción es categoría aparte de la autoficción literaria para esta autora (distinción que, por otra parte, justifica que Campagnoli se decante por el marbete de diario). 
caso performance, representación»[Preciado 2015:181], ¿por qué iba a ser sustancialmente distinto el valor de verdad de un texto autocobaya, autoteórico y autopolítico, al de una novela (autoficcional o no) o, incluso, al de una autobiografía? ¿No hay, paradójicamente, cierta impostura en la enunciación de esta propuesta autoteórica que se pretende no ejercicio literario con potencial emancipador, sino indagación en lo real? En este sentido, como ya ha sido indicado, Campagnoli escoge precisamente la etiqueta de diario íntimo para subrayar que Testo yonqui plantea la «irrupción de lo íntimo en lo público, del espectáculo de la interioridad (...) [como] plataforma de efecto pornográfico» [2018:404]. Pero Campagnoli, si bien cita una definición de Preciado en la que se describe la «pornografía como mecanismo capaz de producción pública de lo privado y espectacularización de la domesticidad» [2010:12], elude comentar, no obstante, un aspecto quizás más relevante de la exhibición [Miguel 2015:140] pública de lo privado a la luz de Pornotopía, según el cual la relación entre realidad y representación se invierte: y es que en este otro ensayo Preciado inscribe dicha espectacularización pornográfica de la intimidad en los cauces performativos de la autoficción [2010:80-85]. Así pues, la autoficción doméstica que la revista Playboy activa «no [consiste en] un desvelamiento de una verdad escondida, sino de un proceso de producción teatral y de construcción narrativa en el que cada detalle ha sido técnicamente orquestado» [2010:83].

De modo análogo al cristal de la Casa Farnsworth [Preciado 2000], el formato del ensayo autobiográfico permite a Preciado crear la ilusión de disolver la frontera entre lo público y lo privado; esta retórica de la transparencia (o de la autenticidad) crea, asimismo, la ilusión de un referente [De Man 1991:113] fundamentado en un precario contrato de lectura referencial (contrato precario porque se alterna con la defensa del carácter performativo del texto). La etiqueta auto-porno-grafía con la que Guillaume Dustan describía sus propias obras [Campagnoli 2018: 403] parece acaso aplicable a Testo yonqui para dar cuenta de la ficcionalización pornográfica (en el sentido recién apuntado) que opera en la representación activa del texto. Si los sentidos de la performatividad en Testo yonqui son, por lo menos, cuatro (son performativos la identidad del yo, el género, la ciencia y la autobiografía/autoficción), se podrían intentar las siguientes hipótesis: aunque en Testo yonqui se trata de diluir la división entre performance y vida [Mauro Rucovsky 2015:59], ¿no es acaso contradictorio desde los parámetros demanianos afirmar una poética snuff (como la que parece implicarse en el principio autocobaya), en la que la represen- 
tación, en cuanto tal, es tomada por real? Por otra parte, ¿podría ser la teoría del sujeto-sustancia (del sujeto testo, por ejemplo [Preciado 2015:35,108]) y de la subjetividad toxicológica una suerte de autojustificación del relato auto-ficcional-biográfico, y no aquel un mero excurso reflexivo acerca de este? ¿ $\mathrm{O}$, más bien, el relato demuestra la capacidad explicativa de la teoría y su adecuación al proceso mediante el cual se deviene sujeto en el presente, independientemente de la propuesta experimental autopolítica?

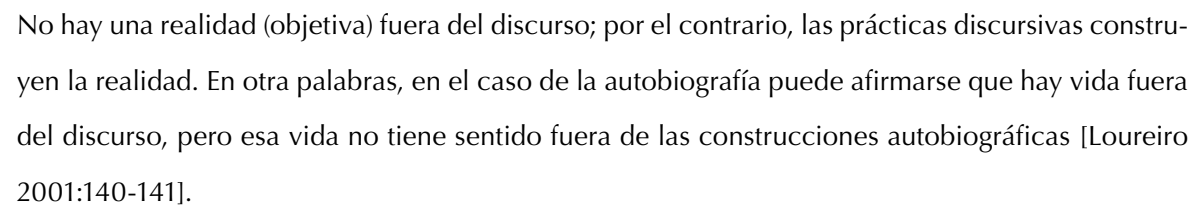

La cita anterior pone de relieve la tensión intrínseca a la noción de lo autobiográfico en Testo yonqui: si bien Preciado parte de Butler, Preciado le critica el olvido de la materialidad en su formulación de la performatividad del género como fenómeno exclusivamente lingüístico [Mauro Rucovsky 2015:30]; sin embargo, en el intento de subsanar dicho olvido, Preciado conduce a la escritura autobiográfica a la paradoja de su relación con el referente: si bien su escritura refleja tanto el problema del lenguaje como el del sujeto, Testo yonqui no se decanta por ninguno (o, lo que es lo mismo, lo hace por ambos), de modo que se afirma una realidad autobiográfica exterior a la escritura, así como, por el contrario, una autocreación de la subjetividad en el ejercicio mismo de la escritura. Si, como dice Loureiro, «debemos ver la autobiografía como un acto performativo y no como una operación cognoscitiva» [2001:141], el saber adquirido mediante el principio autocobaya (y narrado en los capítulos impares de Testo yonqui) tiene entonces un problemático estatuto paradójico, más aún en tanto que la obra manifiesta repetidas veces una concepción performativa de la narración autobiográfica. La conjugación de un saber simultáneamente previo y posterior a su escritura pone en jaque la capacidad de representación afirmada en el principio autocobaya (tanto desde una perspectiva demaniana como lejeuniana), lo que lo sitúa de lleno en el paradigma snuff de la representación [Preciado 2015:242], como la producción de algo real solo en aras de su representación.

La performatividad snuff viola la indecibilidad constitutiva de la textualidad autobiográfica/autoficcional; y esto resulta problemático porque, pese a la conciencia performativa [Preciado 2015:259-260], al situar el texto en una dimensión performativa en el sentido demaniano 
y a la vez oscilar entre ficción y verdad en la valoración de la representación producida desde el principio autocobaya, no se reconocen los límites de la propia capacidad de representación del texto. Por otro lado, en relación con esta cuestión, Testo yonqui se inscribe predominantemente en la matriz demaniana de la auto-ficción-biografía, pero el principio autocobaya excede esa inscripción inicial, no solo por la cuestión recién comentada, sino también porque dicho principio es planteado en términos normativos [Smiraglia 2011:4] y, por ello, vulnera su propio prerrequisito del rechazo al universal para conservar el valor epistémico del saber sobre sí.

Sería irónico que justamente Preciado termine desatendiendo el consejo de Foucault, el de renunciar, como intelectuales, a la vieja función profética. No sólo a la pretensión de decir lo que va a ocurrir en el futuro -cercano, lejano- sino a ejercer la función de legislador: esto es lo correcto, esto es lo que hay que hacer. [Smiraglia 2011:3].

Pese a la crítica al punto de vista universal y a la exigencia del principio autocobaya de rechazar la universalización del contenido experimental (para que sea propiamente autoteoría, y en oposición a «la policía feminista y sus restricciones» [Preciado 2015:259]), hay, sin embargo, una proclama formalmente universal, en tanto que programática [2015:244,252]; por lo que el supuesto rango particular de la propuesta se diluye en su afán universalizador [Mauro Rucovsky 2015:167]. Por ello, en conclusión, parece problemática la concepción normativa de la nueva producción ensayística queer como necesariamente autoteórica y autopolítica.

\section{CONCLUSIONES}

Este artículo ha tratado de problematizar las definiciones taxonómicas de Testo yonqui, tanto en función de lo declarado en la propia obra como en algunos trabajos académicos, para observar el papel de la narración en el seno de un ensayo valorado sobre todo por su vertiente teorética. Se ha desatendido deliberadamente el aspecto material y corporal al que apela el ensayo en aras de dilucidar los parámetros en los que se inscribe la vertiente narrativa del texto, así como los parámetros por los que la narración es leída por parte de la crítica. En el primer apartado, se ha examinado el valor de la narración considerándola desde tres paradigmas de comprensión de lo autobiográfico, a saber: el paradigma performativo, el referencial y el ético, y se ha concluido que la obra, por sus menciones autorreferenciales, se adscribe principalmente a las dimensiones performativa y ética (además de introducir una dimensión política). En el segun- 
do apartado, se han cotejado algunos trabajos a propósito de los marcos de lectura explícitos e implícitos que condicionaban sus lecturas para, por una parte, señalar los problemas derivados de la lectura referencial que adoptaban incuestionadamente algunos de los trabajos consultados, y, por otra parte, retomar la discusión entre autobiografía y autoficción como definiciones de la obra. Por último, en el tercer apartado, se han analizado las tensiones inherentes a la postulación del principio autocobaya en relación con lo expuesto en los epígrafes anteriores, y se ha concluido que tanto la etiqueta de autobiografía como la de autoficción son insuficientes para dar cuenta del sentido pleno de la narración pero que, paradójicamente, dicho principio es planteado según una poética snuff que lo tensiona hacia una comprensión del fenómeno narrativo como performativo a la vez que referencial y que, por ello, guarda una compleja relación con su referente.

En definitiva, la propuesta ensayística de Testo yonqui es valiente y transgresora, y abre una nueva dirección posible para la producción literaria y ensayística queer. Ante la pregunta por la operatividad de un ensayo puro sobre teoría queer para el presente, la respuesta de Testo yonqui es la hibridez y la amalgama de géneros literarios. Pese a que, como corrobora su recepción crítica, la narrativa autobiográfica es considerada inferior a la teorética (y subsidiaria, por tanto, de ella), la tentativa de Testo yonqui reactualiza literariamente la prerrogativa feminista de que lo personal es político. Se apunta a la urgente necesidad de bajar la inflación teórica del feminismo y de la teoría queer para rearmarlos, no solo desde la reflexión académica, sino también desde una producción cultural crítica y autorreflexiva. 


\section{Bibliografía}

ADORNO, Theodor W.: «Notas marginales sobre teoría y praxis», en Consignas. Madrid: Amorrortu, 2003, pp. 159-180.

BUTLER, Judith: El género en disputa. El feminismo y la subversión de la identidad. Barcelona: Paidós, 2014.

—- Cuerpos que importan. Sobre los límites materiales y discursivos del «sexo». Barcelona: Paidós, 2015.

CAMPAGNOLI, Mabel Alicia: Preciados feminismos. Una lectura de Preciado para la antropología filosófica. Málaga: UMA editorial, 2018.

COLL-PLANAS, Gerard: La carne y la metáfora. Una reflexión sobre el cuerpo en la teoría queer. Barcelona/Madrid: Egales, 2012.

DE MAN, Paul: «Retórica de la persuasión (Nietzsche)», en Alegorías de la lectura. Lenguaje figurado en Rousseau, Nietzsche, Rilke y Proust. Barcelona: Lumen, 1990, pp. 143-157.

__: «La autobiografía como desfiguración», en Ángel Loureiro (ed.), La autobiografía y sus problemas teóricos. Suplementos Anthropos, 29 (1991), pp. 113-118.

—_: «El concepto de ironía», en La ideología estética. Madrid: Cátedra, 1998, pp. 231-260.

EDELMAN, Lee: No al futuro. La teoría queer y la pulsión de muerte. Barcelona/Madrid: Egales, 2014.

FOUCAULT, Michel: Historia de la sexualidad. 1. La voluntad de saber. Madrid: Siglo XXI, 2016.

GUSDORF, Georges: «Condiciones y límites de la autobiografía», en Ángel Loureiro (ed.), op. cit., pp. 9-18.

LEJEUNE, Philippe: «El pacto autobiográfico», en Ángel Loureiro (ed.), op. cit., pp. 9-18.

LOUREIRO, Ángel: «Autobiografía: el rehén singular y la oreja invisible», en Anales de Literatura Española, 14 (2001), pp.134-150, consultado en línea:

$<$ http://www.cervantesvirtual.com/obra-visor/anales-de-literatura-espanola--12/html/p0000006. htm\#I_8_>. 
—.: Huellas del otro. Ética de la autobiografía en la modernidad española. Madrid: Postmetropolis, 2016.

LYOTARD, Jean-François; La condición postmoderna. Madrid: Cátedra, 2016.

MAURO RUCOVSKY, Martín de: «Escrituras del yo: ponerle el cuerpo. Ficciones literarias-políticas en primera persona», en Mireia Calafell y Aina Pérez (eds.), El cuerpo en mente. Versiones del ser desde el pensamiento contemporáneo. Barcelona: UOC, 2011.

—- Cuerpos en escena. Materialidad y cuerpo sexuado en Judith Butler y Paul B. Preciado. Barcelona/Madrid: Egales, 2015.

MÉRIDA JIMÉNEZ, Rafael M.: «El espacio autobiográfico del cuerpo trans en España», en El cuerpo: objeto y sujeto de las ciencias humanas y sociales. Barcelona: CSIC, 2010, pp. 1-12, consultado en línea:

$<$ https://www.academia.edu/13430800/EI_espacio_autobiogr\%C3\%A1fico_del_cuerpo_trans_ en_Espa\%C3\%B1a>

——: Transbarcelonas. Cultura, género y sexualidad en la España del siglo XX. Barcelona: Bellaterra, 2016.

MIGUEL, Ana de: «¿Revolución sexual o revolución sexual patriarcal?», en Neoliberalismo sexual. El mito de la libre elección. Madrid: Cátedra, 2015, pp.121-147.

MIRIZIO, Annalisa: «Más allá del feminismo: a propósito de "ficciones autopolíticas" o "autoteorías"», en María Teresa Vera Rojas (ed.), Nuevas subjetividades/sexualidades literarias. Barcelona/ Madrid: Egales, 2012, pp. 173-179.

MOREIRAS, Alberto: «Autografía: pensador firmado (Nietzsche y Derrida)», en Ángel Loureiro (ed.), op. cit., pp. 129-136.

POSADA KUBISSA, Luisa: "Contrasexualidad y "testo yonqui" en Preciado», en ¿Quién hay en el espejo? Lo femenino en la filosofía contemporánea. Madrid: Cátedra, 2019, pp. 223-253.

POZUELO YVANCOS, José María: De la autobiografía. Teoría y estilos. Barcelona: Crítica, 2006. PRECIADO, Paul B.: «Mies-conception: La Casa Farnsworth y el misterio del armario transparen- 
te», Zehar. Revista de Arteleku, 44 (2000), pp. 26-32, consultado en línea: <https://programaddssrr.files.wordpress.com/2013/05/beatriz-preciado-la-casa-farnsworth.pdf>.

—- "Multitudes queer: notas de una política para los "anormales"», Nombres. Revista de Filosofía, 19 (2005), pp. 157-166, consultado en línea: <https://revistas.unc.edu.ar/index.php/ NOMBRES/article/view/2338/1275>.

—_: Pornotopía. Arquitectura y sexualidad en «Playboy» durante la guerra fría. Barcelona: Anagrama, 2010.

——: Testo yonqui. Barcelona: Espasa, 2015.

—_: «My Body Doesn't Exist», in Quinn Latimer and Adam Szymczyk (eds.), The documenta 14 Reader. München/London/New York: Prestel Verlag, 2017, pp. 117-134.

SMIRAGLIA, Romina: «Sobre el principio de autocobaya o de la inmolación como práctica política», Question, 30 (2011), consultado en línea: <https://perio.unlp.edu.ar/ojs/index.php/question/article/view/1048>.

Tiberi, Olga M.: "La autobiografía y el testimonio en la escritura de J. Derrida», Actas del /l Congreso Internacional "Cuestiones Críticas", (2009), pp. 1-11, consultado en línea: <https://docplayer.es/32468251-La-autobiografia-y-el-testimonio-en-la-escritura-de-j-derrida.html>. 